\title{
Differences in the cognitive demands of word order, plural, and subject-verb agreement constructions
}

\author{
JANET L. MCDONALD \\ Louisiana State University, Baton Rouge, Louisiana
}

\begin{abstract}
The syntactic devices of subject-verb-object word order, regular plurals, and subject-verb agreement differ in age of acquisition and susceptibility to error within language-disordered populations. In the present article, the performance of adults on a grammaticality judgment task is used to explore whether such differences are related to working memory (both in terms of an externally imposed load and individual differences in capacity) and phonological ability. The results show that word order, the earliest acquired and most resilient device, is not affected by load, memory span, or phonological ability. Plurals are affected marginally by load and significantly by phonological ability. Agreement, the last acquired and least resilient device, is affected by load, memory span, and phonological ability. Thus, consistent with a processing-based explanation, later acquired and less resilient devices have higher working memory and phonological demands.
\end{abstract}

In the English language, various syntactic devices mark grammatical information in sentences. Such devices vary in how early they are mastered, and how susceptible they are to error in various populations. Three specific devices, in increasing order of both age of acquisition and susceptibility to error, are subject-verb-object (SVO) word order (A dog chases two balls), the regular plural morpheme (two balls ), and the third person singular subject-verb agreement morpheme (A dog chases). This article examines whether these differences in acquisition order and susceptibility to error can be explained by a processing account involving working memory capacity and phonological ability.

\section{Acquisition and Robustness of Syntactic Devices in English}

Word order is very important in the English language. The canonical English SVO word order is mastered early in sentence comprehension, and it is used earlier and more strongly than regular plural and subject-verb agreement morphology (Bates et al., 1984; MacWhinney, Bates, \& Kliegl, 1984; McDonald, 2008). SVO word order has also proven to be a robustly maintained construction in diverse populations, such as aphasics (Wulfeck, Bates, \& Capasso, 1991), late second-language learners (Johnson \& Newport, 1989; McDonald, 2006), and adult native speakers under processing stress (Kilborn, 1991; McDonald, 2006).

In English, the morphological markers of regular plural and third-person subject-verb agreement have identical nonstressed, nonsalient phonological realizations. Thus, phonological ability may play a larger role in their mastery than it does in the mastery of word order. Despite their identical phonological realizations, however, plural and agreement markers still differ in ease of acquisition and susceptibility to error in atypical populations. The regular plural morpheme is acquired before that of third-person agreement in production of native speakers (Brown, 1973) and in grammaticality judgment tasks (McDonald, 2008; Wulfeck, 1993). Earlier or better mastery of plural over agreement morphology has been seen in diverse populations, such as adults with aphasia (Druks, 2006), secondlanguage learners (Goldschneider \& DeKeyser, 2005; Paradis, 2005), children with specific language impairment (Eadie, Fey, Douglas, \& Parsons, 2002; Rice, Wexler, \& Hershberger, 1998), and children under processing stress (Hayiou-Thomas, Bishop, \& Plunkett, 2004).

Factors such as frequency of occurrence, semantic complexity (plural marks number; verb agreement marks number, person, and tense), and syntactic category (markings on verbs are considered more difficult than those on nouns) have been suggested as possible reasons for these differences (Brown, 1973; Goldschneider \& DeKeyser, 2005; Wexler, 1994). In terms of a processing account, such factors may produce larger working memory demands for agreement constructions than for plural constructions. For example, in using verb agreement, the listener must maintain three types of information (number, agreement, tense) across the subject-verb phrase boundary, whereas the listener must maintain only number information within the noun phrase for plurals.

If there is indeed an increased working memory demand for agreement constructions over plurals, processing such 
constructions may suffer under conditions in which working memory resources are limited. This study tested this hypothesis in two ways: (1) by limiting available capacity via an externally imposed digit load, and (2) by examining the effect of individual differences in working memory capacity. Comparing these two methods also enables one to see whether temporary load and individual differences in working memory act similarly. Interestingly, theories of working memory involvement in linguistic processing disagree about the effects of load and individual differences on syntactic processes. Theories that view syntactic and other language processing as using a single pool of resources would predict that both external load and working memory capacity interact with construction type, with more effect on constructions that have a higher processing load (Just \& Carpenter, 1992). Theories that view syntactic processing as using a different set of working memory resources from those affected by load or capacity would predict no such interactions during syntactic processing (Waters \& Caplan, 1996); under these theories, all such interactions would have to be attributable to postinterpretive processing.

An examination of the literature shows that working memory is a promising construct for explaining the order of acquisition and robustness of the constructions investigated here. For English SVO word order, there is very little evidence that either load or individual differences in working memory affect processing (Dick et al., 2001; McDonald, 2006; but see McDonald, 2008). The evidence that load affects processing for plurals is mixed: Some researchers have found evidence of an effect of load (Blackwell \& Bates, 1995), and others have not (Hayiou-Thomas et al., 2004; McDonald, 2006). However, a search of the literature failed to find a study that reported a significant correlation with memory capacity. Several studies on agreement have found decreased performance under load or significant correlations between performance and working memory capacity. Specifically, load has been found to cause more problems with agreement than has been found for no load, as seen in the production of agreement errors in Dutch adults (Hartsuiker \& Barkhuysen, 2006) and poorer grammaticality judgment errors in adults (Blackwell \& Bates, 1995) and children (Hayiou-Thomas et al., 2004). Working memory capacity correlated positively with grammaticality judgment of subject-verb agreement in English-speaking children (McDonald, 2008), and it correlated negatively with number of agreement errors produced by adults (Bock \& Cutting, 1992, Experiment 2; Hartsuiker \& Barkhuysen, 2006- here load interacted with span in such a way that load had an impact only on those with low span).

Arguing against a tie between working memory and the processing of agreement are studies in which no detrimental effect of load has been found (McDonald, 2006), or that have failed to find a correlation between working memory span and performance on agreement tasks (Almor, MacDonald, Kempler, Andersen, \& Tyler, 2001; Bock \& Cutting, 1992, Experiments 1 and 3). These differences in results cannot be explained by the type of load used or by determining whether span was measured using a syntax-free (e.g., item reordering tasks) or a syntaxcontaining (e.g., reading span) measure.

The present experiment was designed to explore the role of working memory capacity and phonological ability in the mastery of three grammatical devices. Participants performed grammaticality judgments of sentences involving SVO word order, regular plural, and subjectverb agreement violations. One group of participants performed this task without an external load, and a second group performed it while under a load. Individual differences in working memory capacity and in phonological ability were measured as well. On the basis of the literature review above, four hypotheses were formulated: (1) The three constructions should differ in performance on the grammaticality judgment task. Paralleling order of acquisition and degree of robustness against error, performance should be best on word order and worst on subjectverb agreement constructions, with plurals falling in the middle. (2) Load should have little impact on word order violations, might or might not have an impact on plural violations, and should have a definite impact on agreement violations. (3) Working memory span should not be strongly correlated with detection of word order or plural violations, but should be correlated with the detection of agreement violations. (4) Detecting word order violations involves noting gross changes in item order, whereas detecting plural and agreement violations involves noting subtle phonological distinctions; therefore, phonological ability should not be correlated with detection of word order violations, but should be correlated with the detection of both plural and agreement violations.

\section{METHOD}

\section{Participants}

Forty native English speakers ranging in age from 18 to 27 years participated. Half were assigned to a no-load group, and half to a seven-digit load group.

\section{Stimuli}

Working memory span. Working memory capacity was measured using a syntax-free size judgment task (Cherry \& Park, 1993; Montgomery, 2000a, 2000b), in which participants were given a list of items that they were to give back in the order of physically smallest to physically largest object. For example, if given pig, door, butterfly, participants were to say, "butterfly, pig, door." Scores on this type of task correlate highly with other measures of working memory used in psycholinguistic research, such as listening span (Cherry, Elliott, $\&$ Reese, 2007). The present task included 3 sets each of lists $3,4,5$, and 6 items long, yielding 12 lists and a total of 54 individual items. All words were recorded individually and then played for participants in sets via the computer. In order to get good discrimination of differences in ability, we took as the span score the total number of words correctly recalled by participants across all lists.

Phonological ability. Phonological ability was measured using a same-different word-pair judgment task developed by Bird, Lambon Ralph, Seidenberg, McClelland, and Patterson (2003). Word pairs consisted of either identical words, or words that differed by virtue of a /d/ or /t/ phoneme on the end of one of the pair. Thus, the task tested people's ability to detect differences on the ends of words, an activity that is conceptually similar to detecting violations of plural and agreement items in the grammatical judgment task (see below). Half of the time, the addition of the $/ \mathrm{d} /$ or $/ \mathrm{t} /$ phoneme 
produced the same word with a morphological change (these were verb past tenses; e.g., roll-rolled); half of the time, it resulted in a new word (e.g., coal-cold). Nine pairs of each type were selected from the list in Bird et al. Each word pair was presented in all possible combinations - that is, in both identical cases (e.g., roll-roll; rolled-rolled) and in both orders of the nonidentical case (e.g., rollrolled, rolled-roll ) - for a total of 72 stimulus item pairs. Since the grammaticality judgment task involved detecting incorrect forms, we took the proportion correct on different trials as the appropriate measure of phonological ability.

Grammatical judgment task. The grammaticality judgment task consisted of 136 sentences. Of these, eight sets of 5 sentences (40 total sentences) tested SVO word order in English: Eight baseline grammatical noun-verb-noun (NVN) sentences (e.g., The girl opens the door) were also presented in their two ungrammatical VNN orders (e.g., Opens the girl the door and Opens the door the girl) and their two ungrammatical NNV orders (The girl the door opens and The door the girl opens). Thirty-two sentence pairs (64 total sentences) tested regular plurals: One sentence of each pair presented the grammatical version (The shopper needed a cart), and one presented the ungrammatical version (The shopper needed a carts). Across sentences there were 16 pairs with singular determiners (a, one) and 16 pairs with plural determiners (three, several, many) that were combined with both singular and plural nouns. Sixteen sentence pairs (32 total sentences) tested subject-verb agreement: One sentence of each pair presented the grammatical version (The girl pads the pillow), and one presented the corresponding ungrammatical version (The girl pad the pillow). Across sentences there were both singular subjects (10 pairs) and plural subjects (6 pairs). For the plural and agreement sentences, both voiced and unvoiced versions of the morpheme were used in all cells in order to ensure that voicing was not a confound. No syllabic realizations of the morphemes occurred, since previous work has shown that the higher salience of these morphemes may interact with phonological ability (McDonald, 2008).

All sentences were digitally recorded by a native speaker. The grammatical and ungrammatical versions of the agreement and plural sentences were formed by splicing the different verbs and nouns, respectively, into the carrier phrase.

\section{Procedure}

The size judgment task was administered first. Participants were told that they would hear lists of words, and that the word report would appear on the screen at the end of each list. They were told to then reorder the list of items from smallest physical object to largest physical object and report this order to the experimenter. The participants began the task with the three-item lists and worked through the remaining lists in order of size. List makeup and order was identical for all participants. The experimenter recorded answers on an answer sheet.

After performing a word-guessing task-run for comparison against bilinguals and therefore not analyzed here - participants performed the grammaticality judgment task. Sentences were auditorily presented via the computer, and participants judged each sentence for grammatical correctness by pushing either the " 1 " key (marked with a "correct" sticker) or the "0" key (marked with an "incorrect" sticker). The task started with the presentation of 3 practice sentences, similar in structure to the test sentences. Then, the 136 test sentences were presented. Blocks were formed in such a way that different versions of the same base sentence did not occur within the same block. Block order was identical across participants; however, the order of item presentation within each block was randomized for each participant. The computer recorded responses.

Half the participants performed the grammaticality judgment task described above, without any external memory load. The other half were asked to remember digits while processing the sentences. Specifically, before each sentence they were presented with an orienting asterisk for $500 \mathrm{msec}$, followed by a random seven-digit string for
1,500 msec. The string then disappeared. They heard the sentence, made their grammaticality judgment by pushing the appropriate key, orally told the experimenter their recall of the seven-digit string, and then proceeded to the next trial.

The phonological judgment task was administered last. Participants were instructed to listen to the word pairs, and to push the "1" key (marked with a "same" sticker) if the words were identical or the " 0 " key (marked with a "different" sticker) if they were not. The computer recorded responses.

\section{RESULTS}

In the analyses presented below, we first tested whether the load and no-load groups were equivalent in their performance on the working memory and phonological judgment tasks. We then analyzed the grammaticality judgment task using a mixed effects model with fixed factors of load and construction type, covariates of span and phonological ability, and the random factors of subject nested with load group and items nested within construction type. Finally, we examined performance on the load task across construction types.

\section{Working Memory Span}

As expected, the performance of the no-load group $(M=45.35)$ did not differ from that of the memory load group $(M=46.75)$ in working memory span $[F(1,38)=$ $2.23, p=.14]$.

\section{Phonological Judgment}

Preliminary analyses yielded no differences between the judgments to items that involved just a morphological difference (roll-rolled) and judgments to items that involved the formation of new words (coal-cold). These results were combined in order to form the phonological ability score. The no-load group $(M=.95)$ did not differ from the load group $(M=.95)$ in phonological ability $[F(1,38)=0.04, p=.84]$.

\section{Grammaticality Judgment}

Preliminary analyses showed that all effects were localized to ungrammatical, rather than grammatical, sentences. This is probably because the grammaticality judgment task is viewed as an error-detection task, in which the default response is to say "correct" unless an overt error is detected; it appears that better error detection occurs in participants with higher memory capacity and higher phonological ability. The results of the mixed effects analysis on ungrammatical sentences showed a significant effect of construction type $[F(2,76)=6.28, p<.005]$. Post hoc tests showed that performance on word order constructions and plurals was similar, and that performance on both was better than that on agreement. Construction type interacted with load $[F(2,75)=4.40, p<.05]$. Analysis of the covariates showed a marginal effect of span $[F(1,37)=3.04, p<$ .09], a significant effect of phonological ability $[F(1,37)=$ $5.25, p<.05]$, and an interaction between construction and span $[F(2,74)=3.05, p=.053]$. To clarify these interactions with construction, individual analyses were run on each construction. (See Table 1 for cell means.) 
Table 1

Proportion Correct Performance (Means and Standard Deviations) on Ungrammatical Sentences by the Three Construction Types and the Two Load Groups

\begin{tabular}{|c|c|c|c|c|c|c|}
\hline & \multicolumn{2}{|c|}{ Word Order } & \multicolumn{2}{|c|}{ Plural } & \multicolumn{2}{|c|}{ Agreement } \\
\hline & $M$ & $S D$ & $M$ & $S D$ & $M$ & $S D$ \\
\hline No load & .87 & .12 & .94 & .06 & .82 & .13 \\
\hline Load & .89 & .15 & .92 & .06 & .75 & .16 \\
\hline
\end{tabular}

As we predicted, the analysis of word order sentences showed no significant effects of load $[F(1,36)=0.51, p=$ $.48]$ span $[F(1,36)=0.01, p=.92]$ or phonological ability $[F(1,36)=0.10, p=.75]$. Plurals showed a marginal effect of load $[F(1,35)=3.96, p<.06]$, no effect of span $[F(1,35)=1.96, p=.17]$, and a significant effect of phonological ability $[F(1,35)=11.69, p<.005]$. Agreement showed an effect of all factors: load $[F(1,36)=7.62, p<$ $.01]$, span $[F(1,36)=7.92, p<.01]$, and phonological ability $[F(1,36)=6.01, p<.05]$.

\section{Load Task}

Performance on the load task did not differ by construction type (word order $M=68 \%$; plural $M=66 \%$; agreement $M=66 \%)[F(2,38)=2.00, p=.15]$. Therefore, there was no trade-off between the grammaticality judgment and memory tasks.

\section{DISCUSSION}

Our hypotheses were largely supported by the results of the experiment. Word order and plural violations proved to be easier to detect than agreement violations. An externally imposed load significantly decreased performance on agreement structures only, whereas it had a marginal effect on plurals. Working memory span significantly correlated with judgments of agreement only. Phonological ability significantly correlated with performance on both plural and agreement structures - structures in which fine phonological discrimination is necessary for one to perform accurately. Thus, agreement constructions, which are later acquired in normal populations and are less robust in disordered and stressed populations, have larger processing demands in terms of both working memory and phonological ability.

Indeed, the factors of working memory and phonological ability may, in part, causally underlie the order of acquisition of certain syntactic devices. Working memory capacity increases across childhood (Gaulin \& Campbell, 1994). Thus, young children may be limited in their ability to consistently use high-demand devices such as verb agreement. Similarly, phonological ability also increases across childhood (Vance, Stackhouse, \& Wells, 2005), so young children may have phonologically imposed limitations on their ability to detect and use devices with subtle, low-salience phonological differences, such as regular plurals and verb agreement.

This same logic applies to the relative robustness of syntactic devices in disordered and stressed populations. Populations such as aphasics and children with specific language impairment are known to have working memory and/or phonological deficits; similar deficits are exhibited by second-language learners in their second language (Bird et al., 2003; McDonald, 2006; Montgomery, 2000a, $2000 \mathrm{~b}$ ). These processing deficits could contribute to poor plural or agreement performance, whereas SVO word order is relatively well maintained. Note that this processing explanation of age and disorder effects stands in contrast to more structural, linguistic, or genetic explanations.

These results indicate that working memory capacity is strongly involved in detecting violations of subjectverb agreement. Both an externally imposed load and low memory span resulted in poorer ability to detect agreement errors. Thus, these results add to those of prior studies using production and comprehension methodologies that have also found either load and/or span to be significantly related to subject-verb agreement. The few prior studies that have failed to find this relationship (Almor et al., 2001; Bock \& Cutting, 1992; McDonald, 2006) show numerical tendencies in the same direction; perhaps the lack of significance in those results is due to power, or to the difficulty of the materials or tasks used.

Working memory seems to be less involved in the detection of plural violations. Working memory capacity was not significantly correlated with plural performance, and no other studies that showed such a correlation were found in a search of the literature. Plurals are not totally immune to working memory pressure, however, since an externally imposed digit load decreased performance marginally in the present study and has done so significantly in some previous work (Blackwell \& Bates, 1995). Working memory demands imposed by load may be more severe than the range covered by individual differences in span, and they may impact phonological processing via rehearsal.

Working memory capacity in the present study was measured using a syntax-free size judgment task. Thus, the interaction between span and construction type cannot be due to an overlap in syntactic components in the span and grammaticality judgment tasks; whatever it is that makes agreement sentences harder is correlated with this nonsyntactic measure. A similar argument holds for the interaction between digit load and construction type. Both of these interactions are easily handled by models of language processing that claim that all processing, be it syntactic or otherwise, is handled by a single pool of resources (Just \& Carpenter, 1992). Models that claim that resources used for syntactic processing are separate from those used by other processes (Waters \& Caplan, 1996) can only account for these interactions if they occur postsyntactically. Although the grammaticality judgment task used here was an offline measure - and thus it is possible that the interactions with span and load occurred postsyntactically - others have also found interactions with span and load using online measures (Hartsuiker \& Barkhuysen, 2006), supporting the single-resource model.

In summary, syntactic devices differ in their processing demands. Working memory (both in terms of load and span) and phonological ability are plausible sources for differences in ease of acquisition and resiliency in disordered populations. 


\section{AUTHOR NOTE}

I thank Matthew Calamia, Alicia Wang, Matthew Rhea, Patrick Johnson, Erin Thomas, Tatiana Falcon, Alina Oster, Colter Frideley, and Johanna Martinez for their help with the experiment. Special thanks go to Matthew Calamia for his patience in recording and splicing the stimulus sentences. Correspondence should be addressed to J. L. McDonald, Department of Psychology, Louisiana State University, Baton Rouge, LA 70803 (e-mail: psmcdo@1su.edu).

\section{REFERENCES}

Almor, A., MacDonald, M. C., Kempler, D., Andersen, E. S., \& TYler, L. K. (2001). Comprehension of long distance number agreement in probable Alzheimer's disease. Language \& Cognitive Processes, 16, 35-63.

Bates, E., MacWhinney, B., Caselli, C., Devescovi, A., Natale, F., \& VenZA, V. (1984). A cross-linguistic study of the development of sentence interpretation strategies. Child Development, 55, 341-354.

Bird, H., Lambon Ralph, M. A., Seidenberg, M. S., McClelland, J. L., \& PATterson, K. (2003). Deficits in phonology and past-tense morphology: What's the connection? Journal of Memory \& Language, 48, 502-526.

BlACKWEll, A., \& BATEs, E. (1995). Inducing agrammatic profiles in normals: Evidence for the selective vulnerability of morphology under cognitive resource limitation. Journal of Cognitive Neuroscience, 7, 228-257.

Bock, K., \& CutTing, J. C. (1992). Regulating mental energy: Performance units in language production. Journal of Memory \& Language, 31, 99-127.

BRown, R. (1973). A first language: The early stages. Cambridge, MA: Harvard University Press.

Cherry, K. E., Elliott, E. M., \& Reese, C. M. (2007). Age and individual differences in working memory: The size judgment span task. Journal of General Psychology, 134, 43-65.

Cherry, K. E., \& PARK, D. C. (1993). Individual difference and contextual variables influence spatial memory in younger and older adults. Psychology \& Aging, 8, 517-526.

Dick, F., Bates, E., Wulfeck, B., Utman, J. A., Dronkers, N., \& Gernsbacher, M. A. (2001). Language deficits, localization, and grammar: Evidence for a distributive model of language breakdown in aphasic patients and neurologically intact individuals. Psychological Review, 108, 759-788.

DRUKS, J. (2006). Morpho-syntactic and morpho-phonological deficits in the production of regularly and irregularly inflected verbs. Aphasiology, 20, 993-1017.

Eadie, P. A., Fey, M. E., Douglas, J. M., \& Parsons, C. L. (2002). Profiles of grammatical morphology and sentence imitation in children with specific language impairment and Down syndrome. Journal of Speech, Language, \& Hearing Research, 45, 720-732.

Gaulin, C. A., \& CAMPBell, T. F. (1994). Procedure for assessing verbal working memory in normal school-age children: Some preliminary data. Perceptual \& Motor Skills, 79, 55-64.

Goldschneider, J. M., \& DeKeyser, R. M. (2005). Explaining the "natural order of L2 morpheme acquisition" in English: A metaanalysis of multiple determinants. Language Learning, 55, 27-77.

Hartsuiker, R. J., \& BarkhuYsen, P. N. (2006). Language produc- tion and working memory: The case of subject-verb agreement. Language \& Cognitive Processes, 21, 181-204.

Hayiou-Thomas, M. E., Bishop, D. V. M., \& Plunkett, K. (2004). Simulating SLI: General cognitive processing stressors can produce a specific linguistic profile. Journal of Speech, Language, \& Hearing Research, 47, 1347-1362.

Johnson, J. S., \& NewPort, E. L. (1989). Critical period effects in second language learning: The influence of maturational state on the acquisition of English as a second language. Cognitive Psychology, 21, 60-99.

Just, M. A., \& CARPENTER, P. A. (1992). A capacity theory of comprehension: Individual differences in working memory. Psychological Review, 99, 122-149.

KILBORN, K. (1991). Selective impairment of grammatical morphology due to induced stress in normal listeners: Implications for aphasia. Brain \& Language, 41, 275-288.

MacWhinney, B., Bates, E., \& Kliegl, R. (1984). Cue validity and sentence interpretation in English, German, and Italian. Journal of Verbal Learning \& Verbal Behavior, 23, 127-150.

McDonald, J. L. (2006). Beyond the critical period: Processing-based explanations for poor grammaticality judgment performance by late second language learners. Journal of Memory \& Language, 55, 381-401.

McDonald, J. L. (2008). Grammaticality judgments in children: The role of age, working memory, and phonological ability. Journal of Child Language, 35, 247-268.

MontGOMERY, J. W. (2000a). Relation of working memory to off-line and real-time sentence processing in children with specific language impairment. Applied Psycholinguistics, 21, 117-148.

Montgomery, J. W. (2000b). Verbal working memory and sentence comprehension in children with specific language impairment. Journal of Speech, Language, \& Hearing Research, 43, 293-308.

PARADIS, J. (2005). Grammatical morphology in children learning English as a second language: Implications of similarities with specific language impairment. Language, Speech, \& Hearing Services in Schools, 36, 172-187.

Rice, M. L., WeXler, K., \& Hershberger, S. (1998). Tense over time: The longitudinal course of tense acquisition in children with specific language impairment. Journal of Speech, Language, \& Hearing Research, 41, 1412-1431.

Vance, M., Stackhouse, J., \& Wells, B. (2005). Speech-production skills in children aged 3-7 years. International Journal of Language \& Communication Disorders, 40, 29-48.

Waters, G. S., \& CAPLAN, D. (1996). The capacity theory of sentence comprehension: Critique of Just and Carpenter (1992). Psychological Review, 103, 761-772.

WEXLER, K. (1994). Optional infinitives, head movement and the economy of derivation in child grammar. In D. Lightfoot \& N. Hornstein (Eds.), Verb movement (pp. 305-350). Cambridge: Cambridge University Press.

WULFECK, B. B. (1993). A reaction time study of grammaticality judgments in children. Journal of Speech \& Hearing Research, 36, 1208-1215.

Wulfeck, B. [B.], Bates, E., \& CAPAsso, R. (1991). A crosslinguistic study of grammaticality judgments in Broca's aphasia. Brain \& Language, 41, 311-336.

(Manuscript received June 15, 2007; revision accepted for publication April 3, 2008.) 